\title{
CASE OF DISARTICULATION
}

\section{OF THE \\ LEFT CONDYLE OF THE LOWER JAW,}

WITH EXCISION OF NEARLY THE LEFT HALF OF THE BONE, ON ACCOUNT OF A VERY LARGE CARTILAGINOUS TUMOUR GROWING FROM, AND OCCUPYING THE SITE OF ALL THIS PART OF THE BONE, SAVE THE CONDYLE AND NECK.

BY

WILLIAM BEAUMON'T, PROTRSSOR OF SURGERY IN THE UNIVERSITY OF TORONTO, CANADA.

Received February 15th.-Read April 23d, 1850.

JAMES M'CugH, æt. 7, was admitted into the Toronto General Hospital (Canada West), on September 17, 1849, presenting a greatly distorted face. The tumour on his admission extended upwards to the zygoma and molar bone, almost covering the temporo-maxillary articulation; it reached downwards to fully an inch below the angle of the jaw, extending inwards into the mouth as far as the mesial plane, backwards, beyond the ramus of the jaw, and forwards to the posterior bicuspid. It pushed the tongue quite to the right of the mesial plane, concealed the velum, and almost completely filled the isthmus faucium. The molar teeth of the upper jaw were deeply imbedded in the tumour, which kept the mouth at all times open, with a constant dribbling of saliva, the upper and lower incisors not meeting by fully half an inch. The tumour was very prominent, the distance from the angle of the mouth to the lobule of the ear on the left side being $5 \frac{1}{2}$ inches, whilst on the right it was but $3 \frac{1}{2}$. The tumour was free from pain, and had at all times been so; it was nearly globular in form, and hard as cartilage in every part of its surface, which within the 
mouth was covered with mucous membrane, and free from ulceration, whilst the soft parts of the cheek covering it externally, though greatly thinned and stretched, were in no ways involved in the disease, being quite unadherent.

The father and mother of the child stated, that it was only three months since they had first observed the tumour, which was then not larger than a nutmeg, and grew from the outer surface of the horizontal portion of the lower jaw. At the end of two months it had acquired its largest size externally, but during the last month had grown inwards into the mouth, and backwards towards the pharynx. As to an occasional cause, it is said, that he received a blow on the left side of the jaw (from a boy's fist), a few months before the tumour was first observed. On admission he could not speak intelligibly, had been unable to masticate for the two previous months, and swallowed with great difficulty, his food being always fluid or semifluid. He was thin and pale, but his general health otherwise pretty good.

Sept. 25th. - The patient being placed on a table, his head raised, and the left side being held uppermost, I commenced the operation (assisted by my friend, Staff-surgeon Widmer, and other gentlemen attached to the hospital), by making a curved incision (the concavity upwards) extending from the lobule of the ear to the angle of the mouth, by which the whole thickness of the cheek, and the commissure of the lips, were divided, exposing the external surface of the tumour, along the line of incision. After tying the facial artery, I dissected, close from off the tumour, the upper flap, containing the parotid duct and a small part of the gland. I now found the tumour firmly wedged in under the molar bone, between which and the tumour I passed a strong ivory spatula, which using as a lever, I forced the tumour downwards from the molar bone, and having thus put its superior attachment, the temporal muscle, \&c., on the stretch, I divided them with a probe-pointed bistoury. I next dissected the under flap from off the lower surface of the tumour, and having passed a scalpel (curved on the flat) along the inner surface of the jaw bone, I separated from it the mylo-hyoid muscle, and other soft 
parts near the bicuspids, the anterior of which I drew, and then with a small straight saw, I cut vertically through the outer wall of the jaw, where this tooth had been drawn. The section was at one stroke completed with strong bone forceps, by laying the edge of one blade in the cleft made by the saw, and passing the other blade close along the inner surface of the jaw. A permanent tooth lodged in the body of the bone would have prevented the further progress of the saw. The left half of the jaw, and the tumour could now be forced so far outwards as to draw the latter in a great measure from the cavity of the mouth, but in doing this I broke off the tumour from the condyle and neck, and upper part of the posterior border of the ramus. The internal pterygoid muscle was then easily separated from the surface of the tumour, (for the natural structure of the jaw from a little below its neck had been entirely absorbed as far as the posterior bicuspid, and its place occupied by the cartilaginous deposit forming the tumour,) and after dividing the mucous membrane on the left side, the tongue, the posterior part of the mylo-hyoid muscle, and inferior dental nerve, the tumour came away; I then proceeded to disarticulate the condyle, which being firmly grasped in the forceps, I drew forwards, opened the joint externally by dividing the external lateral ligament and capsule, and with knives, bluntpointed, and curved on the flat, I cut through the external pterygoid muscle at its insertion; and the capsular ligament all round the condyle, taking care always to keep the edge of the knife scraping against the bone. On removing the condyle I found its cartilage had been absorbed, but the corresponding surface of the inter-articular cartilage was seen quite sound, white, and glistening. Four or five vessels were tied. A large frightful hollow remained where the tumour had been imbedded, at the bottom of which, the internal carotid, but slightly covered, could be felt pulsating, and the internal pterygoid muscle was seen dangling from the projecting pterygoid process. During the operation we were obliged, three or four times, to turn the patient round, so as to place the mouth downwards, in order that the blood 
might the less flow down his throat, and interfere with respiration. Three hare-lip pins were used to hold together the edges of the wound, with strips of adhesive plaster between them, over which cold water dressing was applied; and he was ordered Liquoris Opii Sedativi, $m x$. In half an hour his pulse became 140, and soon 160, but fell in 8 hours to 120 or 130 .

26th, (twenty-four hours after the operation.)-His pulse was 128, and he swallowed well his diet of milk and water. He had slept well the greater part of the night, and had suffered very little pain since the operation.

27.- - He had slept all night, felt an appetite for his food, and his pulse but 120 .

28.-He seemed hardly so well, had slept but little, and the pulse was quicker. I removed all the sutures, and found that union by adhesion had taken place in the whole length of the wound, and that a purulent discharge had commenced from the inner surface of the cheek, and from other parts dissected off the tumour.

30.-He was craving for food, and doing perfectly well.

Oct. 5. - The boy was quite well, and 'walking about the corridors. All the ligatures had come away, and the cicatrix sound, but the purulent discharge in the mouth had not ceased.

23.-A discharge of saliva had been observed for the last two or three days, from a small fistulous opening in the cheek, through which some ligatures had passed. The discharge was perfectly transparent, colourless, and limpid, like water.

Nov. 9.-The salivary fistula I had left to the vis medicatrix naturæ, and at this time it was perfectly healed. The boy had become much stouter and stronger, and could masticate a crust or a piece of meat without any difficulty. The saliva no longer dribbled from his mouth, his deglutition was unimpaired, and his articulation only slightly affected, which probably arose from the habit of not articulating.

Dec. 1, (ten weeks and a half after the operation.) - A cicatrix could be seen on the inside of the left cheek 
near the anterior arch of the velum ; the truncated jaw near the left cuspidating, was soundly covered by an investment like mucous membrane; the external cicatrix was a mere line; no vestige remained of the salivary fistula, and the boy was in perfect health. The right half of the lower jaw was drawn a very little towards the left side, about one eighth of an inch,-I suppose by the unopposed action of the right pterygoid muscles. A section of the tumour showed it to be of dense white cartilage, with numerous small particles of bone interspersed every where throughout the mass, as though it were undergoing ossification. Not a vestige of the original bone remained within the tumour; the ramus, coronoid process, and body of the bone as far as the posterior bicuspid, having been completely absorbed. One of the effects of the absorption of the normal structure of the bone, and the deposit in its stead of the cartilaginous mass forming the tumour, was the diminished adhesion of the insertion of several muscles, viz. the temporal, the masseter, the internal pterygoid, and the posterior portion of the mylohyoid; so that, in separating these muscles from the tumour, the knife was much less needed than it would have been, had the original bone not been absorbed, for these muscles were but loosely inserted into a membranous covering of the tumour, which appeared clearly to be the original periosteum, as it was continuous with that membrane on the posterior border of the ramus near the neck, and also on the body of the jaw just anterior to the tumour. The periosteum probably separated from the jaw, at the time of the bone's absorption; and from diseased actions of nutrition in the periosteum itself, the large cartilaginous mass forming the tumour, no doubt arose. The condyle and neck of the bone were unchanged, and therefore the insertion of the external pterygoid was firm, the division of which and the ligaments of the joint required the most care, as I had here to guard against wounding the internal maxillary and temporal arteries, neither of which, I think, was cut, as no vessel bled so furiously as either of these arteries would, if opened near the bifurcation of the external carotid. The line of incision through the cheek and com- 
missure of the lips, in consequence of the great extensibility of the latter, allowed of the greatest facility in dissecting the soft parts from off the tumour on every side, and also of dividing the jaw at the anterior bicuspid. The line of incision would clearly avoid the parotid duct, but which, in the submaxillary duct, I probably wounded in a subsequent part of the operation, as salivary fistula was evident three or four weeks afterwards, though not till that time suspected.

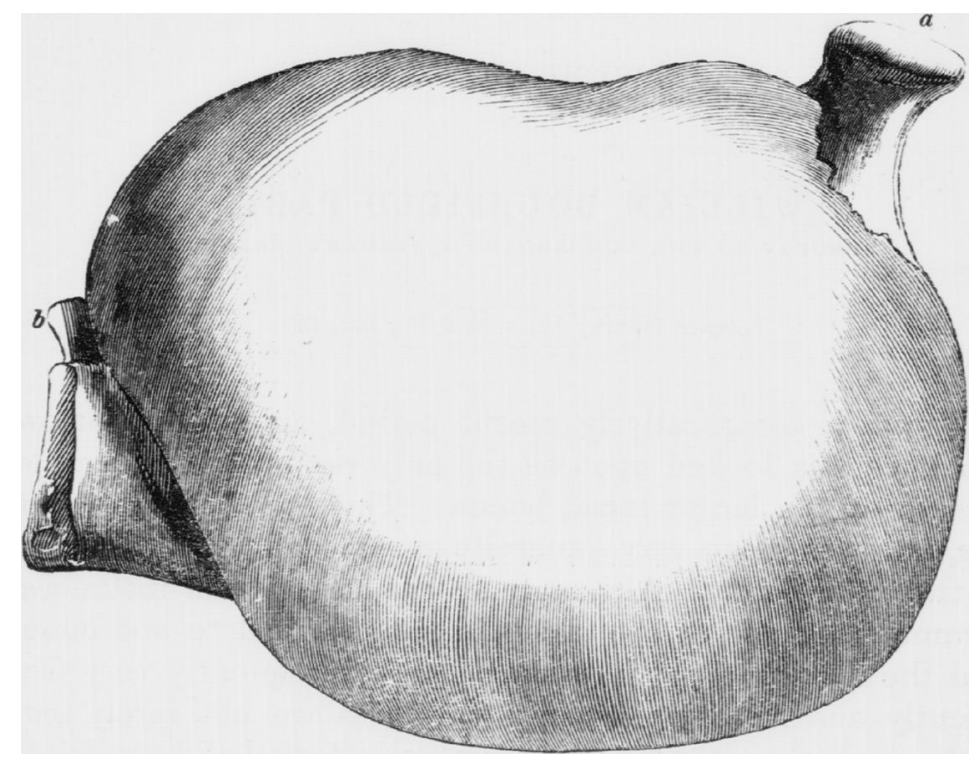

Size and form of the tumour.

Weight 8 oz. avoirdupois.

Longest diameter $3 \frac{4}{10}$ inches.

Shortest diameter $2 \frac{\mathrm{B}}{10}$ inches.

a. Condyle of the jaw.

b. Posterior bicuspid. 